\title{
Exponentially Weighted Moving Average (EWMA) Chart Based on Six Delta Initiatives
}

\author{
KALPESH S. TAILOR
}

Department of Statistics, M. K. Bhavnagar University, Bhavnagar-364001

\section{E-mail: kalpesh_tlr@yahoo.co.in}

Received: December 5, 2017| Revised: February 20, 2018l Accepted: February 28, 2018

Published online: March 01, 2018

The Author(s) 2018. This article is published with open access at www.chitkara.edu.in/publications

\begin{abstract}
A control chart is a graphical device for representation of the data for knowing the extent of variations from the expected standard. The technique of control chart was suggested by W.A. Shewhart of Bell Telephone Company based on three sigma limits. M. Harry, the engineer of Motorola has introduced the concept of six sigma in 1980. In six sigma initiatives, it is expected to produce 3.4 or less number of defects per million of opportunities. Moderate distribution proposed by Naik and Desai is a sound alternative of normal distribution, which has mean and mean deviation as pivotal parameters and which has properties similar to normal distribution. Naik and Tailor have developed various control charts based on this distribution. In this paper an attempt is made to construct a control chart based on six delta initiatives for exponentially weighted moving average chart. Suitable Table for mean deviation is also constructed and presented for the engineers for making quick decisions.
\end{abstract}

Keywords Moderate distribution, EWMA, Six Delta.

\section{INTRODUCTION}

The technique of quality control was developed by W. A. Shewhart (1931). It was based on 3sigma control limits. Mikel Harry (1980), the engineer of Motorola has introduced the concept of six sigma. He developed methods for problem solving that combined formal techniques, particularly relating to measurement, to achieve measurable savings in millions of dollars. The companies, which are practicing Six Sigma, are expected to produce 3.4 or less number of defects per million opportunities

R.Radhakrishnan and P.Balamurugan (2010, 2010, and 2016) have developed six sigma based control charts for the number of defectives, exponentially weighted moving average and standard deviation.

Mathematical Journal of Interdisciplinary Sciences Vol-6, No-2, March 2018 pp. 127-135 
Naik and Desai have proposed an alternative of normal distribution called moderate distribution, which has mean $(\mu)$ and mean deviation $(\delta)$ as pivotal parameters and which has properties similar to normal distribution. Naik and Tailor $(2015,2016)$ have suggested $3 \delta$ (3 mean deviation) control limits based on moderate distribution. On the basis of 3 control limits, they have developed $\bar{X}$-chart, R-chart, s-chart and d-chart. Tailor (2016) has also developed moving average and moving range chart and exponentially moving average chart under moderateness assumption.

Similar to six sigma concept, the concepts of six delta can be developed. So here an attempt is made to develop six delta concepts similar to six sigma concept. The six sigma control limits are based on normality assumption and the control limits are determined by using standard deviation ( $\sigma$-sigma) of the statistic, whereas the six delta control limits are based on moderateness assumption and the control limits are determined by using mean deviation $(\delta$-delta) of the statistic. In six delta initiatives, it is expected to produce 1.7 or less number of defects per million of opportunities. If the companies practicing Six Delta initiatives use the control limits, then no point fall outside the control limits because of the improvement in the quality of the process. Tailor has proposed sample standard deviation(s) chart and sample mean deviation (d) chart based on six delta initiatives. Here an attempt is made to construct a control chart based on six delta initiatives for exponentially weighted moving average. Suitable Table for mean deviation is also constructed and presented for the engineers for making quick decisions.

\section{CONCEPTS AND TERMINOLOGIES}

\section{A. Upper specification limit (USL)}

It is the greatest amount specified by the producer for a process or product to have the acceptable performance.

\section{B. Lower specification limit (LSL)}

It is the smallest amount specified by the producer for a process or product to have the acceptable performance.

\section{Tolerance level (TL)}

It is the difference between USL and LSL, TL = USL-LSL

\section{Process capability (Cp)}

This is the ratio of tolerance level to six times mean deviation of the process.

$$
\mathrm{Cp}=\left(\mathrm{TL} / 6 \sqrt{\frac{\pi}{2}} \delta\right)=(\mathrm{TL} / 10.6369 \delta)=(\mathrm{USL}-\mathrm{LSL}) / 10.6369 \delta
$$


E. Mean deviation $\left(\delta_{6 \delta}\right)$ : For many purposes mean deviation is the most useful measure of dispersion of a set of numbers. It is the mean of absolute deviation.

\section{F. Quality Control Constant $\left(M_{\mathrm{md}}\right)$}

The constant $\boldsymbol{M}_{\mathrm{md}}$ is introduced in this paper to determine the control limits based on six delta initiatives for sample mean deviation.

\section{G. Constant Factor $(\alpha)$}

It is a constant, $0<\propto \leq 1$, which is used to calculate exponentially weighted moving average.

\section{THREE DELTA CONTROL LIMITS FOR EXPONENTIAL WEIGHTED MOVING AVERAGE (EWMA) CHART}

Tailor has proposed exponentially weighted moving average (EWMA) chart under the moderateness with $3 \delta$ control limits. Suppose that the main variable of the process $\mathrm{x}$ follows moderate distribution. The mean of $\mathrm{x}$ is $\mathrm{E}(\mathrm{x})=\mu$ and mean deviation of $\mathrm{x}$ is $\delta_{x}=\delta^{\prime}$. The EWMA function is defined as, $Z_{t}=\propto x_{i}+(1-\propto) Z_{i-1}$, where $0<\propto \leq 1$. If the individual $\bar{X}$ are independent random variables with variance $\frac{\sigma^{2}}{n}$, then
the variance of $Z_{t}$ is defined as

$$
\sigma_{t}^{2}=\frac{\sigma^{2}}{n}\left(\frac{\propto}{2-\propto}\right)\left[1-(1-\alpha)^{2 t}\right]
$$

Therefore

$$
\sigma_{t}=\left[\frac{\sigma^{2}}{n}\left(\frac{\propto}{2-\propto}\right)\left[1-(1-\alpha)^{2 t}\right]\right]^{\frac{1}{2}}=\frac{\sigma}{\sqrt{n}}\left[\left(\frac{\propto}{2-\propto}\right)\left[1-(1-\alpha)^{2 t}\right]\right]^{\frac{1}{2}}
$$

Since we are assuming moderateness, the mean error of $Z_{t}$ is defined as

$$
\delta_{t}=\sqrt{\frac{\pi}{2}} \frac{\delta}{\sqrt{n}}\left[\left(\frac{\propto}{2-\propto}\right)\left[1-(1-\alpha)^{2 t}\right]\right]^{\frac{1}{2}}
$$

Thus, the $3 \delta$ - control limits of EWMA chart can be determined as follows Central line $(\mathrm{C} . \mathrm{L})=E\left(\bar{X}_{t}\right)$

$$
=\overline{\bar{X}}_{t}
$$

Lower control limit (L.C.L) $=E\left(\bar{X}_{t}\right)-3 \delta_{t}$ 
Tailor, KS

$$
\begin{aligned}
& =\overline{\bar{X}}_{t}-3 \sqrt{\frac{\pi}{2}} \frac{\delta}{\sqrt{n}}\left[\left(\frac{\propto}{2-\propto}\right)\left[1-(1-\alpha)^{2 t}\right]\right]^{\frac{1}{2}} \\
& =\overline{\bar{X}}_{t}-5.3184 \frac{\delta}{\sqrt{n}}\left[\left(\frac{\propto}{2-\propto}\right)\left[1-(1-\alpha)^{2 t}\right]\right]^{\frac{1}{2}}
\end{aligned}
$$

Upper control limit (U.C.L) $=E\left(\bar{X}_{t}\right)+3 \delta_{t}$

$$
\begin{aligned}
& =\overline{\overline{X_{t}}}+3 \sqrt{\frac{\pi}{2}} \frac{\delta}{\sqrt{n}}\left[\left(\frac{\propto}{2-\propto}\right)\left[1-(1-\alpha)^{2 t}\right]\right]^{\frac{1}{2}} \\
& =\overline{\overline{X_{t}}}+5.3184 \frac{\delta}{\sqrt{n}}\left[\left(\frac{\propto}{2-\propto}\right)\left[1-(1-\alpha)^{2 t}\right]\right]^{\frac{1}{2}}
\end{aligned}
$$

Where $\overline{\bar{X}}$ and $\delta_{t}$ are typically estimated from preliminary data as sample mean and sample mean deviation.

As $\alpha$ is small and if $t$ increases, the effect of starting value soon dissipates and the mean error converges to its asymptotic value.

i.e $\delta_{t}=\sqrt{\frac{\pi}{2}} \frac{\delta}{\sqrt{n}}\left[\left(\frac{\propto}{2-\propto}\right)\right]^{\frac{1}{2}}$

The control limits for EWMA chart are usually based on the asymptotic mean deviation of the statistic. Hence asymptotic 3-control limits for this chart can be derived as following way,

Central line $(\mathrm{C} . \mathrm{L})=E\left(\bar{X}_{t}\right)$

$$
=\overline{\overline{X_{t}}}
$$

Lower control limit (L.C.L) $=E\left(\bar{X}_{t}\right)-3 \delta_{t}$

$$
\begin{aligned}
& =\overline{\overline{X_{t}}}-3 \sqrt{\frac{\pi}{2}} \frac{\delta}{\sqrt{n}}\left[\left(\frac{\propto}{2-\propto}\right)\right]^{\frac{1}{2}} \\
& =\overline{\overline{X_{t}}}-5.3184 \frac{\delta}{\sqrt{n}}\left[\left(\frac{\propto}{2-\propto}\right)\right]^{\frac{1}{2}}
\end{aligned}
$$


Upper control limit (U.C.L) $=E\left(\bar{X}_{t}\right)+3 \delta_{t}$

$$
\begin{aligned}
& =\overline{\overline{X_{t}}}+3 \sqrt{\frac{\pi}{2}} \frac{\delta}{\sqrt{n}}\left[\left(\frac{\propto}{2-\propto}\right)\right]^{\frac{1}{2}} \\
& =\overline{\overline{X_{t}}}+5.3184 \frac{\delta}{\sqrt{n}}\left[\left(\frac{\propto}{2-\propto}\right)\right]^{\frac{1}{2}}
\end{aligned}
$$

\section{SIX DELTA BASED CONTROL LIMITS FOR EXPONENTIAL WEIGHTED MOVING AVERAGE (EWMA) CHART}

Fix the tolerance level $(\mathrm{TL})$ and process capability $\left(\mathrm{C}_{\mathrm{p}}\right)$ to determine the process mean deviation $\delta$ (termed as $\left.\delta_{6 \delta}\right)$, which is calculated from $\mathrm{Cp}=$ $(\mathrm{TL} / 10.6369 \delta)$. For a specified TL and $\mathrm{C}_{\mathrm{p}}$ of the process, the values of $\delta_{6 \delta}$ is calculated, and presented in table 2 . The value of $M_{m d}$ is obtained by using $P\left(Z \leq M_{m d}\right)=1-\alpha_{1}$, where $\alpha_{1}=1.7 \times 10^{-6}$ and $Z$ is a standard moderate variate. Thus, the control limits for six delta based control chart for EWMA are determined as,

$$
\begin{gathered}
C L_{\delta_{6 \delta}}=\overline{\bar{X}}_{t} \\
L C L_{{ }_{6^{\prime}}}=\overline{\bar{X}}_{t}-M_{m d^{\prime} 6^{\prime}}\left[\frac{1}{n}\left(\frac{\propto}{2-\propto}\right)\left[1-(1-\alpha)^{2 t}\right]\right]^{\frac{1}{2}} \\
U C L_{{ }_{6}{ }^{\prime}}=\overline{\bar{X}}_{t}+M_{m d^{\prime}}{ }^{\prime} \cdot\left[\frac{1}{n}\left(\frac{\propto}{2-\propto}\right)\left[1-(1-\alpha)^{2 t}\right]\right]^{\frac{1}{2}}
\end{gathered}
$$

Similarly, asymptotic $6 \delta$-control limits for this chart can also be derived.

\section{AN EMPIRICAL STUDY FOR EWMA CONTROL CHART AND COMPARISION OF THREE DELTA LIMITS AGAINST SIX DELTA INITIATIVES}

To illustrate the use of EWMA control chart with three delta and six delta limits, a data set is taken from Lucas J. M and Crosier R.B. The data, together with the corresponding EWMA values, are shown in Table 1. The target value is taken to be 0 . Three delta and six delta control limits are computed from this data set, and control charts are plotted under these two limits. 
Tailor, KS

Table 1: Data set.

\begin{tabular}{|c|c|c|}
\hline $\mathbf{t}$ & Observed value & $\begin{array}{c}\text { EWMA } \\
=+(1-)\end{array}$ \\
\hline 0 & - & 0.0 \\
\hline 1 & 1.0 & 0.25 \\
\hline 2 & -0.5 & 0.063 \\
\hline 3 & 0.0 & 0.047 \\
\hline 4 & -0.8 & -0.165 \\
\hline 5 & -0.8 & -0.324 \\
\hline 6 & -1.2 & -0.543 \\
\hline 7 & 1.5 & -0.032 \\
\hline 8 & -0.6 & -0.174 \\
\hline 9 & 1.0 & 0.119 \\
\hline 10 & -0.9 & -0.135 \\
\hline 11 & 1.2 & 0.198 \\
\hline 12 & 0.5 & 0.274 \\
\hline 13 & 2.6 & 0.855 \\
\hline 14 & 0.7 & 0.817 \\
\hline 15 & 1.1 & 0.887 \\
\hline 16 & 2.0 & 1.166 \\
\hline 17 & 1.4 & 1.224 \\
\hline 18 & 1.9 & 1.393 \\
\hline 19 & 0.8 & 1.245 \\
\hline
\end{tabular}

(a) Three delta control limits (asymptotic) for EWMA chart:

Here the parameters of the EWMA are chosen to be $\alpha=0.25, \delta=1, \mathrm{n}=1$ and the target mean is taken as zero. Hence, the three delta control limits are found as,

$\mathrm{LCL}=-2.010, \mathrm{CL}=0$ and $\mathrm{UCL}=2.010$

(b) Control limits (asymptotic) based on six delta initiatives for EWMA chart: 
For a given data set $\mathrm{USL}=1.393, \mathrm{LSL}=-0.032, \mathrm{TL}=1.393+0.032=1.425$ $\approx 1.43$ and $\mathrm{C}_{\mathrm{p}}=1.5$. The value of $\delta_{6 \delta}=0.0896$, which is found from the Table $2, M_{m d}=5.815$ which is calculated from $P\left(Z \leq M_{m d}\right) 1=-\alpha_{1}$, where $\alpha_{1}=1.7 \times 10^{-6}$. The other parameters are chosen to be $\alpha=0.25, \mathrm{n}=1$ and the target mean is taken as zero.. Hence, the control limits based on six delta initiatives for EWMA chart for a specified TL and $M_{m d}$ are determined as, $C L_{6 \delta} \boxminus 0, L C L_{6 \delta}=-0.1969, U C L_{6 \delta}=0.1969$

Table 2: Values of for a specified $\mathrm{C}_{\mathrm{p}}$ and $\mathrm{TL}$

\begin{tabular}{cccccc}
\hline $\mathbf{T L}$ & $\mathbf{1 . 4 1}$ & $\mathbf{1 . 4 2}$ & $\mathbf{1 . 4 3}$ & $\mathbf{1 . 4 4}$ & $\mathbf{1 . 4 5}$ \\
$\mathbf{C p}$ & & & & & \\
\hline 1.0 & 0.1326 & 0.1335 & 0.1344 & 0.1354 & 0.1363 \\
1.1 & 0.1205 & 0.1214 & 0.1222 & 0.1231 & 0.1239 \\
1.2 & 0.1105 & 0.1112 & 0.1120 & 0.1128 & 0.1136 \\
1.3 & 0.1020 & 0.1027 & 0.1034 & 0.1041 & 0.1049 \\
1.4 & 0.0947 & 0.0954 & 0.0960 & 0.0967 & 0.0974 \\
1.5 & 0.0884 & 0.0890 & 0.0896 & 0.0903 & 0.0909 \\
1.6 & 0.0828 & 0.0834 & 0.0840 & 0.0846 & 0.0852 \\
1.7 & 0.0780 & 0.0785 & 0.0791 & 0.0796 & 0.0802 \\
1.8 & 0.0736 & 0.0742 & 0.0747 & 0.0752 & 0.0757 \\
1.9 & 0.0698 & 0.0703 & 0.0708 & 0.0713 & 0.0717 \\
2.0 & 0.0663 & 0.0667 & 0.0672 & 0.0677 & 0.0682 \\
2.1 & 0.0631 & 0.0636 & 0.0640 & 0.0645 & 0.0649 \\
2.2 & 0.0603 & 0.0607 & 0.0611 & 0.0615 & 0.0620 \\
2.3 & 0.0576 & 0.0580 & 0.0585 & 0.0589 & 0.0593 \\
2.4 & 0.0552 & 0.0556 & 0.0560 & 0.0564 & 0.0568 \\
2.5 & 0.0530 & 0.0534 & 0.0538 & 0.0542 & 0.0545 \\
\hline
\end{tabular}

(c) EWMA-charts for data set given in Table 1 based on three delta and six delta limits: 


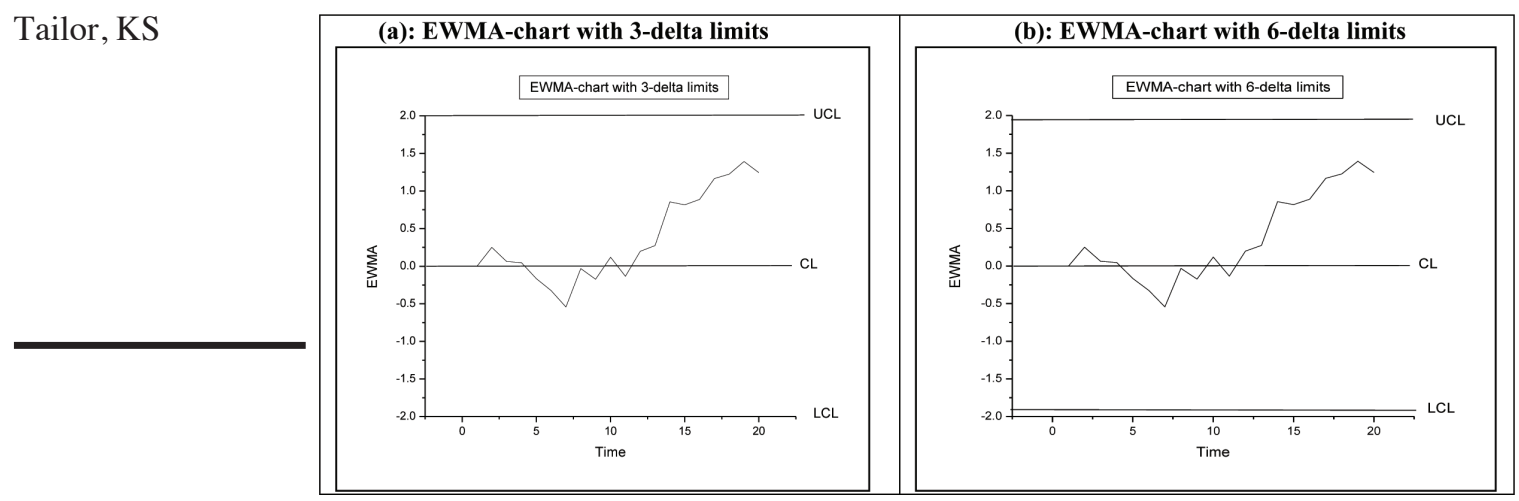

Figure 1

\section{SUMMARY AND CONCLUSION}

In this paper, EWMA chart is discussed under three delta and six delta control limits with an illustration. From figure 1, it can be seen that the production process is in statistical control in both the cases. If we compare the UCL and LCL of both the types of charts, six delta control limits are always smaller than the three delta control limits. So it can be concluded that the chart under six delta control lifts are more effective towards detecting the shift in the value of EWMA than the charts under three delta control limits. This is a next generation control chart technique and it will replace existing six sigma technique. So it is recommended that the control charts under six delta control limits should be used for the best results.

\section{REFERENCES}

[1] Hunter J. S. (1986): The Exponentially Weighted Moving Average, Journal of Quality Technology, 18, 203-210.

[2] Lucas J.M. and Crosier R.B. (1982): Fast Initial Response for CUSUM Quality Control Schemes, Technometrics, 24, 199-205

[3] Lucas J.M. and Saccucci M.S. (1990): Exponentially Weighted Moving average Schemes, Properties and Enhancements, Technometrics, 32, 1-29

[4] K.S.Tailor(2016): Moving Average And Moving Range Charts Under The Assumption Of Moderateness And Its 3 Control Limits, Sankhya Vignan, December-2016, 2, 18-31

[5] K.S.Tailor(2017): Exponentially Weighted Moving Average (EWMA)Charts Under The Assumption Of Moderateness And Its 3-delta Control Limits, Mathematical Journal of Interdisciplinary Sciences(MJIS), March-2017, Vol. 5, 2, 121-129 
[6] K.S.Tailor(2017): Sample Standard Deviation(s) Chart Under The Assumption Of Moderateness And Its Performance Analysis, International Journal of Research-Granthaalayah (IJRG), Vol. 5, Issue 6, June- 2017, 368-377

[7] K.S.Tailor(2017): Sample Mean Deviation (d) Control Chart Based on Six Sigma Initiatives, Sankhya Vignan, June-2017, 28-36

[8] K.S.Tailor(2017): Sample Mean Deviation (d) Chart Under the Assumption of Moderateness and its Performance Analysis Under Normality Against Moderateness, International Journal of Engineering and management research(IJEMR), Vol. 7, Issue 4,July-August -2017, 292-296

[9] R.Radhakrishnan and P.Balamurugan(2016):Construction of control chart based on six sigma initiatives for standard deviation ,American International Journal of Research in Science, Technology, Engineering \& Mathematics, June- August , pp. $245-248$

[10] R.Radhakrishnan and P.Balamurugan(2010):Six Sigma based Control charts for the number of defectives, Proceedings of the 2010 International Conference on Industrial Engineering and Operations Management (IEOM 2010) organized by Bangladesh Society of Mechanical Engineers, Dhaka, Bangladesh, Jan 9-10, (2010a), 92.

[11] R.Radhakrishnan and P.Balamurugan(2010):Six Sigma based Exponentially Weighted Moving Average Control Chart, Indian journal of Science and Technology (IJST), Vol.3, No. 10, October, pp. 1052-1055

[12] Roberts S.W. (1959): Control chart Tests Based on Geometric Moving Average Charts. Technometrics, Vol.-1, No.-3, pp .239-250

[13] V.D. Naik and K.S. Tailor (2015):On performance of and R-charts under the assumption of moderateness rather than normality and with 3 control limits rather than 3 control limits, VNSGU Journal of Science and Technology, Vol.4, No. 1, 243-255

[14] W.A. Shewhart(1931):Economic Control of Quality of Manufactured Product, New York: Van Nostrand, .

[15] W.A. Shewhart(1931):Economic Control of Quality of Manufactured Product, New York: Van Nostrand, .
Exponentially Weighted Moving Average (EWMA) Chart Based on Six Delta Initiatives 